\title{
Beneficial Effects of Natural Environment Therapy for Atopic Dermatitis
}

\author{
Seo Kyoung Suk ${ }^{1}$, Chang-Gue Son ${ }^{2}$ \\ ${ }^{1}$ Center of counseling, Daejeon oriental hospital in Daejeon University \\ ${ }^{2}$ Liver and Immunology Research Center, Oriental Medical College in Daejeon University
}

\begin{abstract}
Objectives: Natural environment therapy is considered as an option for atopic dermatitis. This study was aimed to examine the beneficial effects of natural environment therapy among patients with atopic dermatitis who have moved in an atopy-free village.

Methods: The questionnaire-based survey was conducted from parents of 20 children with atopic dermatitis (12 male and 8 female, median age 8 years, ranging from 6 to 13 years). The questionnaire consisted of 10 questions for the changes of two typical symptoms of pruritus and sleeping difficulty after moving into an atopy-free village.

Results: $75.0 \%$ and $88.9 \%$ of patients have a family history (at least one parent and one of siblings respectively) of allergic disorders. The median staying period of patients was 27.6 months (ranging from 2 to 55 months). The score indicating pruritus was significantly improved from $6.2 \pm 2.8$ into $4.8 \pm 1.8(\mathrm{p}<0.05)$, and sleeping difficulty was also improved from $5.7 \pm 2.9$ into $4.3 \pm 2.1 \quad(\mathrm{p}<0.05)$ too.

Conclusions: This study suggests that the natural environmental therapies could be a choice for patients with atopic dermatitis, which should be studied further for their scientific evidence and mechanisms.
\end{abstract}

$\overline{K e y}$ Words : Atopic dermatitis, Environmental therapy, Korean medicine

\section{Introduction}

Atopic dermatitis (AD) is a chronic inflammation with the pruritic skin disorder. This disease has a high prevalence rate approximately $17.9 \%$ to $11.2 \%$ for children aged 6-14 years in Korea ${ }^{1)}$, and the prevalence is continuously increasing especially in developed countries ${ }^{2}$. The etiology of $\mathrm{AD}$ is unclear, but the contributing factors include the genetic factor, frequent exposure to air pollutions, and westernized changes of food and housing ${ }^{3,4)}$.

Atopic dermatitis seriously affects quality of life in patients as well as their families ${ }^{5}$, however no radical and effective conventional therapy exist at this moment ${ }^{6}$. The emollients, ultraviolet light exposure, and corticosteroids in severe cases are three common managements ${ }^{7}$. Therefore, adapted alternative and complementary therapies or various folk-remedies have received attention from patients with $\mathrm{AD}^{8)}$. Although some herbal drugs significantly improved symptom severity of $\mathrm{AD}$, still those drugs haven't been approved as a commercial therapeutics for $\mathrm{AD}^{9,10)}$.

On the other hand, it is well known that $A D$ prevalence is higher in urban areas than rural ${ }^{11,12}$. The environmental-host interactions have influence

\footnotetext{
- Received : 26 January 2017

- Revised : 25 May 2017

- Accepted : 25 May 2017

- Correspondence to : Chang-Gue Son

Liver and Immunology Research Center, Daejeon Oriental Hospital of Daejeon University,

176-9, Daeheung-ro, Jung-gu, Daejeon, 34929 Republic of Korea

Tel : +82-42-229-6807, Fax : +82-42-257-6398, E-mail : ckson@dju.ac.kr
} 
on the risk of developing allergic diseases including $\mathrm{AD}^{13,14)}$. In addition, there are reports that nature -staying atopy camp reduces the atopic symptoms and blood parameters ${ }^{15,16)}$. These facts strongly propose that residence with natural environment would be an important option in management of $\mathrm{AD}$.

This study was aimed to examine the beneficial effects of the natural environment therapy (termed herein for the staying in natural environments with smallest conventional therapeutics as much as possible) among patients with $\mathrm{AD}$ who have moved from metropolis into a designed village (called as Atopy-free village) in Geumsan of South Korea.

\section{Participants and methods}

\section{Participants}

All kindergarten and elementary schoolchildren who have been staying in Atopy-free village, and previously diagnosed with $\mathrm{AD}$ and had the duration of staying $>$ one month at Atopy-free village participated in this study. Total 20 participants consisting of 12 male (median age 9 year, ranging from $6 \sim 11$ years) and 8 female (median age 9 year, ranging from $6 \sim 13$ years) were enrolled.

\section{Methods}

A questionnaire was given to the mothers of 20 children participants between July to August 2016. The questionnaire consisted of 10 questions for the demographic information, family history, and duration of staying at Atopy-free village as well as changes of two main $\mathrm{AD}$ symptoms, pruritus and sleeping difficulty before the movement and during the recent month respectively. For quantitative assessment of pruritus and sleeping difficulty, a numerical self-rating scale (NRS) was used; mothers scored each item from 1 to 10 (1 indicating no symptom versus 10 indicating endurable status). All participants' parents fully comprehended the purpose of the study, and provided written informed consent.

\section{Atopy-free village}

The Atopy-free village was founded at by Geumsan city, a Korean local government in 2010. This village is located at Sanggok-ri Gunbook-myun Geumsa-gun South Korea, surrounded by multiple mountains including Seadae Mountain with 978m height. The concept of Atopy-free village is composed of chemical-low environments including mud-timber buildings with environment-friendly materials and organic food in housing as well as in school life. The kindergarten and elementary schoolchildren were educated with mainly outdoor activities relatively other than schools in city.

\section{Statistical analysis}

The data were analyzed whether pruritus and sleeping difficulty were improved after moving into Atopy-free village comparing to before. The paired $\mathrm{t}$-test was conducted for statistical analysis using PASW Statistics 17 program, and if $p$ value was less than 0.05 , it was considered as statistically significant.

\section{Results}

\section{Characteristics of participants}

The average duration of staying at Atopy-free village was $27.7 \pm 19.8$ months (male $20.9 \pm 16.2$ and female $37.8 \pm 21.4$ months). Seventy-five percent of children had at least one parent with allergic disorders including $\mathrm{AD}$, allergic rhinitis or asthma respectively. In case they had brother or sister, $88.9 \%$ of children had a sibling with one of above allergic disorders (Table 1).

\section{Improvement of pruritus and sleeping difficulty}

The NRS average score for pruritus was $6.2 \pm 2.8$ 


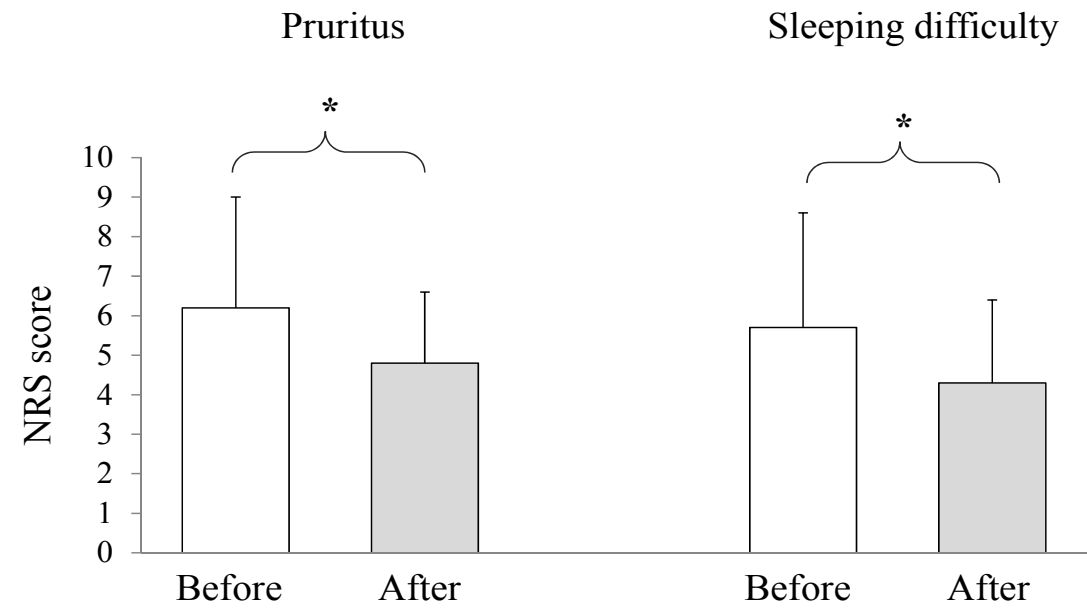

Fig. 1. NRS score between before and after of movement into Atopy-free village. For pruritus and sleeping difficulty, patients scored the changes of symptoms using a numerical self-rating scale (NRS) between before movement and during recent one month. *indicates $\mathrm{p}\langle 0.05$ using pared t-test.

(male 7.2 \pm 2.4 and female 4.6 \pm 2.8 ), whereas the pruritus severity was significantly improved into $4.8 \pm 1.8 \quad(\mathrm{p}<0.05$, male $4.9 \pm 2.1$ and female $4.5 \pm 1.4)$ respectively. The sleeping difficulty was also improved significantly from $5.7 \pm 2.9$ (male 7.1 \pm 2.3 and female $3.8 \pm 1.8)$ to $4.3 \pm 2.2(\mathrm{p}<0.05$, male $4.6 \pm$ 2.4 and female $3.5 \pm 2.5$ ) respectively (Fig. 1).

\section{Discussion}

$\mathrm{AD}$ has profound impacts on patient and family quality of life, however no satisfactory preventive or treatment strategy exist. The exploration of linkage between modern urban life and various diseases resulted in attending natural environments as one of therpeutics ${ }^{17}$. Several Korean studies presented that forest activity-based atopy camps reduced $\mathrm{AD}$ symptoms and induced immunomodulation ${ }^{18,19)}$. One survey study in Korea reported that many parents having children suffering from $\mathrm{AD}$ expected the beneficial effects of natural environment therapy, and $55.2 \%$ of parents had considered moving to a rural $\operatorname{area}^{20)}$.
In order to get a clue for the clinical benefit of staying in natural environments without any conventional therapeutics as much as possible (termed as natural environment therapy in this study), the present study examined the improvement of $\mathrm{AD}$ symptoms. The average residence period at Atopy-free village was $27.7 \pm 19.8$ months (ranging from 2 to 55 months, Table 1). The pruritus is a typical symptom of $\mathrm{AD}$, and it usually becomes worse at night, resulting in sleep disturbance ${ }^{21)}$. The changes of pruritus and sleeping status therefore could be proper parameters for clinical assessment in $\mathrm{AD}$ patients. In the present study, parents reported that both pruritus and sleeping difficulty significantly reduced after movement into Atopy-free village (Fig. 1). $\mathrm{AD}$ generally occurs in children, which impairs the emotional and intellectual development, and then be very stressful to their parents ${ }^{22}$. Accordingly, the assessment by parents in current study would be convincing. In fact, half of $\mathrm{AD}$ is known to disappear in cases of early onset and mild severity, however likely present study cases, family history of atopy and severe $\mathrm{AD}$ are associated with poor 
Table 1. Subject Characteristics

\begin{tabular}{|c|c|c|c|c|}
\hline \multicolumn{2}{|c|}{ Item } & Male & Female & Total \\
\hline \multicolumn{2}{|c|}{ Number } & $12(60.0 \%)$ & $8(40.0 \%)$ & $20(100 \%)$ \\
\hline \multicolumn{2}{|c|}{ Median age (year, range) } & $9(6-11)$ & $9(6-13)$ & $9(6-13)$ \\
\hline \multirow{2}{*}{ Family history } & Parents ${ }^{\S}$ & $10(83.3 \%)$ & $5(62.5 \%)$ & $15(75.0 \%)$ \\
\hline & Sibling ${ }^{\#}$ & 9 of $10(90.0 \%)$ & 7 of $8(87.5 \%)$ & 16 of $18(88.9 \%)$ \\
\hline \multicolumn{2}{|c|}{ Duration of staying (month) } & $20.9 \pm 16.2$ & $37.8 \pm 21.4$ & $27.7 \pm 19.8$ \\
\hline
\end{tabular}

\$. \# included if at least one of both parents and sibling had any atopic disorder among $\mathrm{AD}$, allergic rhinitis or asthma respectively.

prognosi $^{23}$. The patients in our study showed high rate of family history for allergic disorders; $75 \%$ of parents as well as $88.9 \%$ of sibling (Table 1).

The Atopy-free village was founded by Geumsan city, a Korean local government. The basic strategy is living within natural environments at a countryside surrounded by mountains, and mud-timber buildings and organic food in housing and school life. The relationship between diets with incidence of $\mathrm{AD}$ is well known, and then organic food is believed to reduce the risk of $\mathrm{AD}^{24,25)}$. All patients in present study had moved into the village from metropolises for their severe AD. They were not satisfied with conventional therapies, and quitted them. The uncontrolled $\mathrm{AD}$ impairs the life's quality of patients as well as their families ${ }^{26,27)}$, which they would sometimes prefer to move to a countryside.

Above findings proposes the potential of environmental therapy for children with $\mathrm{AD}$. The forest environment-based programs showed partially positive effectiveness in the management in alcoholics and elderly hypertensive patients ${ }^{28,29}$. Our previous studies also observed the reduction of pruritus in children with $\mathrm{AD}$ during short-term environment-based atopy camp and long-term residence in Atopy-free village ${ }^{15,30)}$. For assessment of the changes of $\mathrm{AD}$ symptoms, above studies adapted the objective tools and parameters such as score of SCORAD and EASI or serum IgE concentration respectively. In present study, the parents assessed the changes of two typical $\mathrm{AD}$ symptoms, pruritus and sleeping difficulty. This would be a week point of our study along with the relatively small number of participants. The parents' assessment after observation for long term however could present the alternative evaluation of $\mathrm{AD}$ symptoms comparing to an examination at certain time point, because AD-related symptoms and biomarkers would be changeable depending on the time points.

Taken together, this study provides important clinical information for development of the natural environment therapy for parents of $\mathrm{AD}$. There are, however, still large tasks to be done, including multiple scientific studies to extend evidence for clinical effect as well as its mechanisms.

\section{Acknowledgments}

This research was supported by the "Leaders Industry-university Cooperation" Project, supported by the Ministry of Education, Science \& Technology (2016B-0016-010107), and the grant of the Traditional Korean Medicine R \& D Project, Ministry of Health \& Welfare, Republic of Korea (HI16C-0112-000015).

\section{Conflicts of interest}

The authors declare that there is no conflict of interests.

\section{References}

1. Ahn K, Kim J, Kwon HJ, Chae Y, Hahm MI, Lee KJ, et al. The prevalence of symptoms of 
asthma, allergic rhinoconjunctivitis, and eczema in Korean children: Nationwide cross-sectional survey using complex sampling design. J Korean Med Assoc. 2011;54(7):769-78.

2. Thomsen SF. Epidemiology and natural history of atopic diseases. Eur Clin Respir J. 2015;2: 24642.

3. Benn CS, Melbye M, Wohlfahrt J. Cohort study if sibling effect, infectious disease, and risk of atopic dermatitis during first 18 months of life. BMJ. 2004;150:284-90.

4. Baek JO, Hong S, Son DK, Lee JR, Roh JY, Kwon HJ. Analysis of the prevalence of and risk factors for atopic dermatitis using an ISAAC questionnaire in 8,750 Korean children. Int Arch Allergy Immunol. 2013;162(1):79-85.

5. Drucker AM, Wang AR, Qureshi AA. Research Gaps in Quality of Life and Economic Burden of Atopic Dermatitis: The National Eczema Association Burden of Disease Audit. JAMA Dermatol. 2016;152(8):873-4.

6. O'Toole A, Thomas B, Thomas R. The care triangle: determining the gaps in the management of atopic dermatitis. J Cutan Med Surg. 2013;17(4):276-82.

7. Forte WC, Sumita JM, Rodrigues AG, Liuson D, Tanaka E. Rebound phenomenon to systemic corticosteroid in atopic dermatitis. Allergol Immunopathol (Madr). 2005;33(6):307-11.

8. Goddard AL, Lio PA. Alternative, Complementary, and Forgotten Remedies for Atopic Dermatitis. Evid Based Complement Alternat Med. 2015; 2015:676897.

9. Tan HY, Zhang AL, Chen D, Xue CC, Lenon GB. Chinese herbal medicine for atopic dermatitis: a systematic review. J Am Acad Dermatol. 2013;69(2):295-304.

10. Lee J, Bielory L. Complementary and alternative interventions in atopic dermatitis. Immunol Allergy Clin North Am. 2010;30(3):411-24.

11. Lee SY, Kwon JW, Seo JH, Song YH, Kim BJ,
$\mathrm{Yu}$, et al. Prevalence of atopy and allergic diseases in Korean children: associations with a farming environment and rural lifestyle. Int Arch Allergy Immunol. 2012;158(2):168-74.

12. Sałaga-Pylak M, Pikuła A, Janowska J, Jasinska A, Barnas E, Borzecki A. The occurrence of allergic illnesses among children at the pre-school age in the rural and urban area. Ann Univ Mariae Curie Sklodowska Med. 2004; 59(1):321-4.

13. Ruxrungtham K. The complex link of the environment on allergic rhinitis and atopic dermatitis. Asian Pac J Allergy Immunol. 2016; 34(1):1-2.

14. Kantor R, Silverberg JI. Environmental risk factors and their role in the management of atopic dermatitis. Expert Rev Clin Immunol. 2016:1-12.

15. Lee NR, Kim HG, Seo KS, Son CG. Therapeutic potential of atopy-camp : a pilot study. J Korean Oriental Medicine. 2010;31(6):40-6.

16. Shin OS, Han MH, Park G, Jang JY. The Effect of Family Participated Healing Camps with the Application of Family Life Habit Improvement on Atopic Dermatitis. J Korean Institute of Forest Recreation. 2013;17(3):75-83.

17. Shin YK, Baik JH, Chae JH. Application of Environmental Therapy: Focused on Forest Therapy and Hydrotherapy. Korean J Stress Research. 2010;18(2):167-79.

18. Lee SI, Ahn KM, Lee KS, Kwon HG, Cho HJ, Kim JH. The Influence of National Park Healing Camp on Patients with Atopic Dermatitis. J Korean Institute of Forest Recreation. 2010; 14(2):45-50.

19. Seo JC, Dong SH, Kang IS, Yeun KN, Cheong JT, Yoo Y, et al. The Clinical Effects of Forest Camp on Children with Atopic Dermatitis. J Korean Institute of Forest Recreation. 2012; 16(3):21-31.

20. Son CG. Demand Survey for Application of 
Environmental Therapy for Atopic Dermatitis. J Korean Med. 2014;35(2):34-40.

21. Reuveni H, Chapnick G, Tal A, Tarasiuk A. Sleep fragmentation in children with atopic dermatitis. Arch Pediatr Adolesc Med. 1999; 153(3):249-53.

22. Gupta MA, Gupta AK, Schork NJ, Ellis CN. Depression modulates pruritus perception: a study of pruritus in psoriasis, atopic dermatitis, and chronic idiopathic urticaria. Psychosom Med. 1994;56:36-40.

23. Wananukul S, Chatproedprai S, Tempark T, Phuthongkamt W, Chatchatee P. The natural course of childhood atopic dermatitis: a retrospective cohort study. Asian Pac J Allergy Immunol. 2015;33(2):161-8.

24. Kummeling I, Thijs C, Huber M, van de Vijver LP, Snijders BE, Penders J, et al. Consumption of organic foods and risk of atopic disease during the first 2 years of life in the Netherlands. Br J Nutr. 2008;99(3):598-605.

25. Johnston GA, Bilbao RM, Graham-Brown RA. The use of dietary manipulation by parents of children with atopic dermatitis. Br J Dermatol. 2004;150(6):1186-9.

26. Ben-Gashir MA, Seed PT, Hay RJ. Quality of life and disease severity are correlated in children with atopic dermatitis. Br J Dermatol. 2004; 150:284-90.

27. Kim DH. Factors Associated with Parenting Stress of Mothers of School-aged Children with Atopic Dermatitis. Korean J Stress Research. 2011;19(2):115-21.

28. Shin WS, Shin CS, Yeoun PS. The influence of forest therapy camp on depression in alcoholics. Environ Health Prev Med. 2012;17(1):73-6.

29. Sung J, Woo JM, Kim W, Lim SK, Chung EJ. The effect of cognitive behavior therapy-based "forest therapy" program on blood pressure, salivary cortisol level, and quality of life in elderly hypertensive patients. Clin Exp Hypertens. 2012;34(1):1-7.

30. Sung HK, Seo KS, Son CG. A Observational Study on Children with Atopic Dermatitis in Atopic-Free Village. J Pediatr Korean Med. February. 2014;28(1):01-06. 